\title{
Fetal Head Circumference
}

National Cancer Institute

\section{Source}

National Cancer Institute. Fetal Head Circumference. NCI Thesaurus. Code C158297.

A circumferential measurement of the fetal head at the widest point. 